\title{
Atualidades/Actualities
}

\section{AÇÃO PREVENTIVA EM PROBLEMAS VISUAIS DE ESCOLARES*}

\author{
Edméa Rita Temporini**
}

\begin{abstract}
TEMPORINI, E. R. Ação preventiva em problemas visuais de escolares. Rev. Saúde públ, S. Paulo, 18: 259 - 62, 1984.

RESUMO: Apresenta-se abordagem preventiva de problemas visuais de escolares, considerando os níveis de prevenção em Saúde Pública (Leavell e Clark). E destacada a importância da atuaçăo em educação para a saúde na escola, dirigida à promoção da saúde ocular e à prevenção de distúrbios oftalmológicos, buscando a adoção de condutas acertadas do indivfduo, em termos pessoais e coletivos. A linha geral da programação é descrita sucintamente, concluindo pela necessidade da manutenção dos seus propósitos e bom nível, embora já implantada como rotina de serviço.
\end{abstract}

UNITERMOS: Oftalmologia sanitária. Saúde escolar. Educação em saúde pública.

Programas de prevenção da cegueira vêm recebendo ênfase nas últimas décadas, em muitos países, por parte de órgãos e instituições do setor saúde.

Dados apresentados pela Organização Mundial da Saúde (OMS) apontam cerca de 40 milhões de pessoas cegas no mundo, das quais dois terços seriam compostos de casos preveníveis ou curáveis. A situação mostra-se mais grave nos países em desenvolvimento, onde se localizam $80 \%$ dos casos de cegueira ${ }^{6}$.

Se examinarmos os problemas oculares à luz dos níveis de prevenção de Leavell e Clark $^{2}$, verificaremos a importância da conduta individual ou coletiva como fator condicionante na obtenção de resultados adequados. A atuação nos níveis de prevenção primária, secundária ou terciária exige ações do indivíduo e da comunidade para a sua efetivaçăo.

E sobejamente conhecido que o comportamento do indivíduo se torna fator determinante das condições de saúde que ele apre- senta, bem como do nível de saúde da comunidade da qual ele faz parte. 0 simples fato de colocar serviços de saúde ao alcance da população, por si só, não assegura níveis desejáveis de higidez. A saúde decorre, de um lado, da decisão pessoal, que se baseia em conhecimentos e valores sócio-culturais, onde interfere, de maneira decisiva, o complexo família-sociedade, por meio de fatores restritivos ou impulsionadores; de outro lado, depende de medidas facilitadoras em relaça $\mathrm{a}$ :

1) acesso ao conhecimento científico,

2) desenvolvimento de atitudes favoráveis à saúde $e$

3) meios que permitam ao individuo a prática desse conhecimento.

Em relação a problemas oftalmológicos, reveste-se de suma importância a formação de mentalidade preventiva na população, relativa às causas da cegueira e à maneira de evitá-las.

A OMS, já há algum tempo, vem incentivando a organização de esforços conjuntos

* Apresentado ao V Congresso Brasileiro de Prevenção da Cegueira no Grupo de Trabalho: O Deficiente Visual e a Sociedade - Curitiba, junho/1982.

** Do Departamento de Prática de Saúde Pública da USP - Av. Dr. Arnaldo, 715 - 01255 - São Paulo, SP - Brasil. 
TEMPORINI, E. R. Ação preventiva em problemas visuais de escolares. Rev. Saúde públ, S. Paulo, 18: $259-62,1984$.

de grupos de especialistas e da comunidade, com a finalidade da prevenção de problemas oftalmológicos, buscando criar uma consciência preventiva ao lado da ação correspondente. Segundo a OMS, "programas efetivos requerem ação comunitária sistemática para eliminar a cegueira e os distúrbios visuais"s.

Evidencia-se, então, o papel fundamental da área de Educação em Saúde na Oftalmologia Sanitária, como processo dinâmico, cujos objetivos se direcionam no sentido da população vir a adotar condutas acertadas, em termos pessoais e coletivos, em todos os níveis de prevenção.

A cegueira na infância é particularmente importante, seja pelos índices com que se apresenta nos paises em desenvolvimento, seja por representar um encargo sócio-econômico mais grave.

Os especialistas são concordes quanto à importância que a visão assume, desde a mais tenra idade, no processo de aprendizagem, bem como quanto à necessidade da descoberta e tratamento precoces dos distúrbios oculares, como formas de minimização e solução de tais problemas ${ }^{1}$.

Na maioria dos países desenvolvidos é obrigatório o exame da acuidade visual ao redor de 3-4 anos, realizado por oftalmologista, pediatra, ortoptista, enfermeiro ou outro elemento devidamente treinado.

Considerando a limitação de recursos dos países em desenvolvimento, a verificação periódica da acuidade visual em crianças e adul. tos é recomendada como parte significativa de programas preventivos ${ }^{5}$. Informe da OMS ressalta que "a acuidade visual é o indicador mais pronto da função visual. A aplicação desse teste não requer treinamento prolongado dos examinadores, nem grande esforço para obter a cooperação ou a compreensão dos pacientes, nem requer o uso de equipamento sofisticado"s.

Coerente com essas diretrizes, vêm-se de. senvolvendo desde 1973, no Estado de São Paulo, atividades sistematizadas de oftalmo. logia sanitária junto às escolas da rede estadual de ensino, com os propósitos de identificar distúrbios oculares em alunos e prover a devida assistência, respaldando-se em ações de educação em saúde, além de desenvolver atividades de investigação da problemática oftalmológica existente ${ }^{3}$. Tais procedimentos estao voltados precipuamente para a prevenção primária e secundária - promoção da saúde ocular, proteção específica, diagnóstico precoce e pronto tratamento.

Essa programação já se encontra integrada nas atividades de rotina das escolas estaduais e das unidades sanitárias. 0 professor orientado aplica teste de acuidade visual nos seus alunos e realiza a observação de sinais e sintomas indicativos de problemas. $O$ encaminhamento a exame médico-oftalmológico baseia-se nessas duas fontes de informação, sendo utilizadas, de forma coordenada, as agências de saúde existentes na comunidade (estaduais, municipais e demais órgãos de prestação de serviços) para o atendimento especializado ${ }^{4}$.

0 papel do educador em saúde é básico para o desencadeamento de todas essas ações:

1) quando transmite o conteúdo técnicocientífico e administrativo da programação ao professor, incentivando-o a assumir a parcela que lhe cabe, ou seja, a identificação do seu aluno portador de distúrbio visual, mediante a aplicação de teste e a observação dirigida de saúde;

2) quando mantém o entrosamento com as agências de saúde envolvidas no atendimento dos casos encaminhados;

3) quando coordena e supervisiona a atuação dos professores-multiplicadores, a ni. vel de região;

4) quando busca soluções em conjunto com a familia e a escola para a correção ou minimização dos problemas detectados.

Existe um componente educativo intrínseco a tais ações para que sejam levadas a cabo, uma vez que pressupõem a adoção de comportamentos do pessoal da escola, em especial do professor, familia, pessoal das agências de saúde e comunidade, na busca de solução dos problemas visuais do escolar.

Tendo em vista a importância da identificação precoce dos distúrbios oculares, é considerado prioritário o grupo populacio- 
TEMPORINI, E. R. Ação preventiva em problemas visuais de escolares. Rev. Saúde públ., S. Paulo, 18: $259 \cdot 62,1984$.

nal dos escolares mais jovens, ou seja, de pré-escola e de 1 ạ série do lọ grau.

A nivel da Secretaria de Estado da Educação (SE) a verificação da acuidade visual nas escolas vem sendo prevista anualmente, inserida no "Cronograma de Atividades" da SE, publicado no Diário Oficial do Estado, o que confere cunho de realização obrigatória à atividade.

Ainda, a fim de prover assistência oftalmológica às crianças carentes de recursos e excedentes à possibilidade de atendimento das agências de saúde governamentais, o Departamento de Assistência ao Escolar - DAE (Secretaria da Educação), desde 1976, vem dispondo anualmente de verba para pagamento de consulta especializada.

Além disso, o material de apoio para a execução das ações - tabela de Snellen, manual de orientação e instrumentos de encaminhamento e controle - vem sendo distribuído sistemática e efetivamente às escolas, mediante orientação.

Observa-se que se tem mantido o esforço conjunto do pessoal da escola, pais, comunidade em geral, Prefeituras Municipais, agências de saúde e pessoal técnico, no sentido da promoção da saúde ocular, prevenção de agravos e recuperação de problemas visuais da criança.

Concluindo, o escolar está sujeito a dis túrbios visuais que interferem no seu rendimento e que, futuramente, poderão trazer limitações a sua vida profissional e social. A escola, instituição que consegue aglutinar grande número de crianças, permite uma ação programada e maciça de cunho preventivo, no que se refere à promoção da saúde ocular ou no diagnóstico precoce e pronto tratamento dos casos identificados. Deve-se destacar que, no Estado de São Paulo, o educador de saúde pública que atua no sistema de ensino, vem sendo o elemento catalisador para que tais açōes ocorram.

E absolutamente fundamental que se mantenham vivos os propósitos e o bom nivel da programação de oftalmologia sanitária nas escolas, evitando o desinteresee e possível desgaste que poderiam decorrer da própria condição de rotina de serviço já implantada.

TEMPORINI, E. R. [Preventive action with regard to the visual problems of schoolchildren]. Rev. Saúde públ., S. Paulo, 18: 259 - 62, 1984.

ABSTRACT: The preventive approach to schoolchildren's visual problems is presented, taking into consideration the levels of Public Health prevention (Leavell \&Clark). The importance of health education in schools with regard to the promotion of eye health and the prevention of ophthalmological problems is indicated in the attempt at the adoption of appropriate individual behavior both on the personal and the collective level. The general outline of the program is briefly described with a concluding appeal for the maintance of its objectives and continued effective functioning, though already established as a routine service.

UNITERMS:Sanitary ophthalmology. School health education.

\section{REFERÊNCIAS BIBLIOGRÁFICAS}

1. KARA-JOSÉ, N. \& TEMPORINI, E. R. Avaliaf̧ão dos critérios de triagem visual de escolares de primeira série do primeiro grau. Rev. Saúde públ., S. Paulo, 14: 205-14, 1980.

2. LEAVELI, H. R \& CLARK, E. G. Medicina preventiva. São Paulo, McGraw-Hill do Brasil, 1976.
3. PLANO de Oftalmologia Sanitária Escolar; elaborado por Comissão Conjunta da Secretaria da Saúde e Secretaria de Educação. São Paulo, Serviço de Oftalmologia Sanitária do Instituto de Saúde, 1976.

4. TEMPORINI, E. R. O plano de oftalmologia sanitária escolar do Estado de São Paulo: aspectos técnico-administrativos. São 
TEMPORINI, E. R. Ação preventiva em problemas visuais de escolares. Rev. Saúde públ, S. Paulo, 18: $259 \cdot 62,1984$.

Paulo, 1980. [Dissertação de mestrado Faculdade de Saúde Pública da USP].

5. WORLD HEALTH ORGANIZATION. Guidelines for programmes for the prevention of blindness. Geneva, 1979.
6. WHO urges massive support for the prevention of blindness. Int. J. Hith Educ., 21(2): 120, 1978.

Recebido pare publicaçdo em 17/02/1984 Aprovedo para publicaço em 26/03/1984 